\title{
An experimental study of low-level laser therapy in rat Achilles tendon injury
}

\author{
Jon Joensen • Nils Roar Gjerdet • \\ Steinar Hummelsund • Vegard Iversen • \\ Rodrigo Alvaro B. Lopes-Martins • Jan Magnus Bjordal
}

Received: 29 November 2010 / Accepted: 6 April 2011 /Published online: 6 May 2011

(C) The Author(s) 2011. This article is published with open access at Springerlink.com

\begin{abstract}
The aim of this controlled animal study was to investigate the effect of low-level laser therapy (LLLT) administered $30 \mathrm{~min}$ after injury to the Achilles tendon. The study animals comprised 16 Sprague Dawley male rats divided in two groups. The right Achilles tendons were injured by blunt trauma using a mini guillotine, and were treated with LLLT or placebo LLLT 30 min later. The injury and LLLT procedures were then repeated 15 hours later on the same tendon. One group received active LLLT $(\lambda=$
\end{abstract}

J. Joensen $\cdot$ S. Hummelsund

Department of Physiotherapy, Faculty of Health and Social

Science, Bergen University College,

Bergen, Norway

J. Joensen $(\varangle) \cdot$ J. M. Bjordal

Physiotherapy Research Group, Department of Public Health and

Primary Health Care, Faculty of Medicine and Dentistry,

University of Bergen,

Bergen, Norway

e-mail: jon.joensen@hib.no

N. R. Gjerdet

Department of Clinical Dentistry, Faculty of Medicine and

Dentistry, University of Bergen,

Bergen, Norway

V. Iversen

Faculty of Education, Bergen University College,

Bergen, Norway

R. A. B. Lopes-Martins

Laboratory of Pharmacology and Experimental Therapeutics, Department of Pharmacology, Institute of Biomedical Sciences, University of São Paulo, Cidade Universitária,

São Paulo, Brazil

J. M. Bjordal

Centre for Evidence-Based Practice, Bergen University College,

Bergen, Norway
$904 \mathrm{~nm}, 60 \mathrm{~mW}$ mean output power, $0.158 \mathrm{~W} / \mathrm{cm}^{2}$ for $50 \mathrm{~s}$, energy $3 \mathrm{~J}$ ) and the other group received placebo LLLT 23 hours after LLLT. Ultrasonographic images were taken to measure the thickness of the right and left Achilles tendons. Animals were then killed, and all Achilles tendons were tested for ultimate tensile strength (UTS). All analyses were performed by blinded observers. There was a significant increase in tendon thickness in the active LLLT group when compared with the placebo group $(p<0.05)$ and there were no significant differences between the placebo and uninjured left tendons. There were no significant differences in UTS between laser-treated, placebo-treated and uninjured tendons. Laser irradiation of the Achilles tendon at $0.158 \mathrm{~W} / \mathrm{cm}^{2}$ for $50 \mathrm{~s}(3 \mathrm{~J})$ administered within the first $30 \mathrm{~min}$ after blunt trauma, and repeated after $15 \mathrm{~h}$, appears to lead to edema of the tendon measured 23 hours after LLLT. The guillotine blunt trauma model seems suitable for inflicting tendon injury and measuring the effects of treatment on edema by ultrasonography and UTS. More studies are needed to further refine this model.

Keywords LLLT · Acute injury · Rat Achilles . Ultrasonographic imaging $\cdot$ Edema $\cdot$ Ultimate tensile strength

\section{Introduction}

Animal models are commonly used in tendon disorder research. They have the advantages of incorporating invasive evaluation techniques, and the possibility for detailed tissue examination and analysis of biochemical substances. These models may be useful in reproducing some aspects of human tendon disorders because in animal models it is easier to control single factors. 
In experimental studies on animal tendons, partial or total surgical tenotomy is the most commonly used method for inducing injury [1-8]. Another, nonsurgical, method of injury induction has been introduced in a few studies of tendons in small rodents [9-11]. In this model, an external blunt trauma is inflicted by a mini guillotine where a block falls down from a fixed height and crushes the tendon. After such an injury in a mini guillotine, significant histological changes have been found when compared to healthy tendons [9-11]. However, other relevant outcome measures such as edema and the tendon's ability to withstand load, have not yet been investigated.

The primary purpose of tendons is to transmit tensile load from muscles to bone insertions. Their biomechanical properties can be measured by their ultimate tensile strength (UTS). UTS is an outcome measure of a the tendon's ability to tolerate tensile load and elongation [12]. In two studies on rat tendons where UTS was used as an outcome measure, healthy rat Achilles tendon had UTS values of $42.5 \pm 5.5 \mathrm{~N}$ (mean $\pm \mathrm{SD})$ [13] and $48 \pm 11.0 \mathrm{~N}$ [14].

Low-level laser therapy (LLLT) is considered to act in a biomodulatory manner through light absorption by photoreceptors, which stimulates cells and modulates inflammatory processes [15-19]. Studies performed in a variety of different pathological conditions including injured animal tendons are frequent in the LLLT literature. In most of these LLLT studies, tendons were treated daily for 3 to 21 days $[1-5,9,11]$. Observed histopathological changes in tendons receiving LLLT include increased collagen production [1], improved collagen bundle organization $[2-4,11]$, and an increased number of small blood vessels [9]. Some studies have investigated the effect of LLLT within the first $24 \mathrm{~h}$ after an acute inflammation. After induction of inflammation followed by three or four LLLT sessions, tissue receiving LLLT exhibited reduced concentrations of inflammatory markers and cells compared to no-treatment controls [20, 21].

In the clinical setting tendon disorders are common. Tendon loading seems to be a risk factor for developing tendon disorders, particularly in the upper extremities among manual workers [22] and in the lower extremities among athletes [23]. Acute tendinitis may occur after unfamiliar repetitive movement, friction and pressure during tendon loading, and is often seen in the Achilles tendons of military recruits after long marches [24]. Chronic tendinopathies have a more complex etiology and manifestation, and development of chronic tendinopathies may be gradual and less clearly associated with tendon loading episodes. Age seems to be of importance, and partial or complete tendon ruptures are strongly correlated with age [25]. Developing experimental animal models which accurately mimic the clinical situation in chronic tendinopathies is a challenge, and the ultimate experimental model has yet to be found [26]. Soslowsky et al. [27] developed a rat model of repetitive loading of the supraspinatus in treadmill running, but some aspects including genetics and the influence of pre-experimental structural tendon defects, have not been catered for. Another, as yet unused, possibility for mimicking tendinopathies is to repeat infliction of injury by blunt trauma.

During the last two decades, ultrasonographic imaging (US) has become a popular diagnostic tool for assessment of musculoskeletal disorders [28]. US is reported to have high accuracy in diagnosing disorders in superficial human tendons [28-30].

The aim of this study was to investigate the effects of LLLT administered $30 \mathrm{~min}$ after an Achilles tendon injury inflicted by a mini guillotine. The outcome was measured as tendon edema on US and tendon tensile strength.

\section{Method}

Animals

The study animals comprised 16 male rats (Sprague Dawley SD M; Taconic Europe, Denmark) weighing 250-300 g, which were divided in two groups. The rats were housed four and four in individually ventilated cages under a light cycle of 12 hours light/12 hours dark, in an atmosphere of humidity $55 \%$ and a temperature range of $20-22^{\circ} \mathrm{C}$, and with water and food ad libitum.

\section{Instruments}

Mini guillotine The mini guillotine comprised a block weight of $200 \mathrm{~g}$ with a blunt edge $2 \mathrm{~mm}$ wide that was dropped from $20 \mathrm{~cm}$ guided by supports (Fig. 1).

Laser The laser emitted radiation at a wavelength $904 \mathrm{~nm}$ (Irradia, Sweden) and was operated in pulsed mode. The peak power was $20 \mathrm{~W}$, the pulse width $200 \mathrm{~ns}$ and the frequency $700 \mathrm{~Hz}$. The mean output power was $60 \mathrm{~mW}$, the spot size $0.38 \mathrm{~cm}^{2}$ and the power density $60 \mathrm{~mW} / 0.38 \mathrm{~cm}^{2}$ $\left(=0.158 \mathrm{~W} / \mathrm{cm}^{2}\right)$. Two identical single diode laser probes were use, one with active laser and the other an inactive/ placebo probe. Irradiation was applied for $50 \mathrm{~s}$. Thus $3 \mathrm{~J}$ was delivered from the active laser.

Ultrasonography The US instrument was a GE Logiq e (GE Healthcare, Minneapolis, MN) with a $12 \mathrm{MHz}$ linear probe.

Material test system A servohydraulic testing machine (MTS 810; MTS, Minneapolis, MN) equipped with a calibrated load cell of $500 \mathrm{~N}$ and a position transducer of $100 \mathrm{~mm}$ was used. 


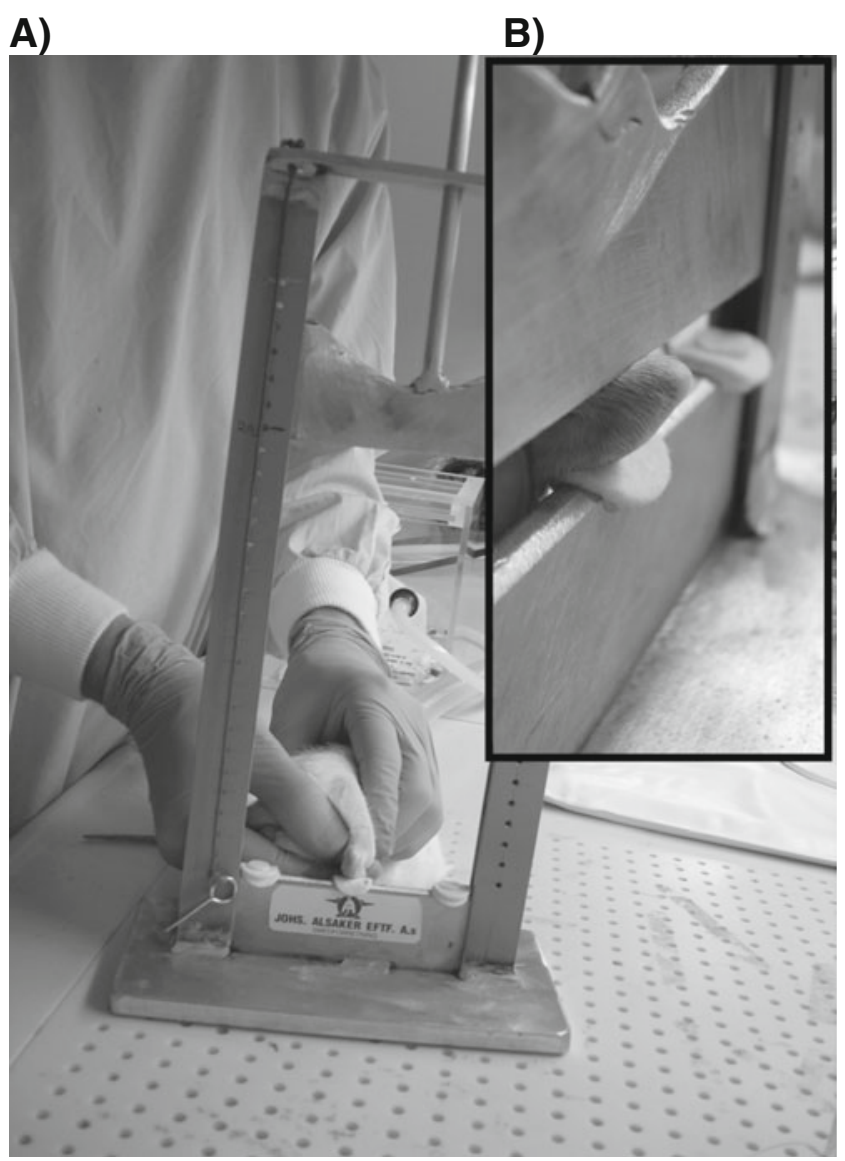

Fig. 1 a Mini guillotine with rat positioned for Achilles injury. b (insert) Close-up of the tendon crush location

The deformation rate was $0.25 \mathrm{~mm} / \mathrm{s}$. The load and deformation data were sampled continuously during the test.

\section{Experimental procedure}

One investigator (J.M.B.) labeled one laser probe with blue tape and the other with yellow tape. The code for active and placebo probes were not disclosed until the statistical analysis was done. The laser probe output was then measured to determine which probe had been the active one. The main outcome measures were tendon thickness (including the peritendon) as measured on ultrasonographic images and UTS. The study was approved by the local animal laboratory committee at the University of Bergen (application no. 20102676).

The experimental procedure (Fig. 2) was carried out in six steps:

1. The animal was anesthetized with isoflurane (Isoba) using an Isotec vaporizer. Under anesthesia, the animal's right ankle was positioned in full dorsal flexion in the mini guillotine such that the edge of the block hit just proximal to the insertion on the calcaneus (Fig. 1). This procedure was carried out by J.J. After injury, the animal's tail was marked to distinguish it from others in the cage, and was put back into the cage. All animals in each group were subjected to this procedure.

2. Half an hour after injury, the animal was again anesthetized and the injured area was treated for $50 \mathrm{~s}$ with either active $(3 \mathrm{~J})$ or placebo LLLT delivered to one single point (performed by J.J.). A new mark was put on the tail. This treatment procedure was repeated in all eight animals in each group.

3. The next day, $15 \mathrm{~h}$ after the first injury, the same area of the right Achilles tendon was again injured using the guillotine according to the procedure in step 1 and half an hour after later the area was treated for $50 \mathrm{~s}$ with LLLT according to the procedure in step 2. This procedure was performed by J.J.

4. On day three, $23 \mathrm{~h}$ after the second injury, US was performed bilaterally on the right and left Achilles tendon (carried out by S.H.). The imaging depth was set to $2 \mathrm{~cm}$, with three focus areas around the first centimeter (Fig. 3). The animal was anesthetized and the Achilles tendon area was scanned in both the longitudinal and transverse planes, two images in both planes. The longitudinal plane was scanned with the whole length of the Achilles tendon in the image. Tendon thickness (including peritendon) in the longitudinal plane images was measured from the os calcaneus up to the deeper layer of the skin (Fig. 3). When scanning the Achilles tendon and the adjacent structures in the transverse plane the probe was moved distally from the knee until it met the os Calcaneus, and images were acquired in this position. The thickness in the transverse plane was measured as the vertical distance within the anterior and posterior border of the peritendon. In the statistical analyses the averages of the measurements from two US images were used. Each animal's tail was marked after the US scan was complete.

5. The animals were anesthetized $2 \mathrm{~h}$ later and given $0.4 \mathrm{ml}$ intraperitoneal anesthetic (Mebumal $50 \mathrm{mg} / \mathrm{ml}$; $1 \mathrm{ml}$ contains $54.9 \mathrm{mg}$ pentobarbital sodium, $400 \mathrm{~g}$ propylene glycol, $150 \mathrm{mg}$ strong alcohol and distilled water to $1 \mathrm{ml}$ ). The animals were killed by injection of $1 \mathrm{ml}$ saturated potassium chloride solution to cause cardiac arrest. The skin overlying the right gastrocnemius muscle was released from the calcaneus to the proximal part of the triceps surae muscle. The Achilles tendon was then released with scissors, and the muscle fibers were removed from the tendons with a scalpel. Water containing $9 \%$ sodium chloride was sprayed over the tendon. The tendon was put into a small plastic bag, labeled and stored in a refrigerator at $4^{\circ} \mathrm{C}$. The same 


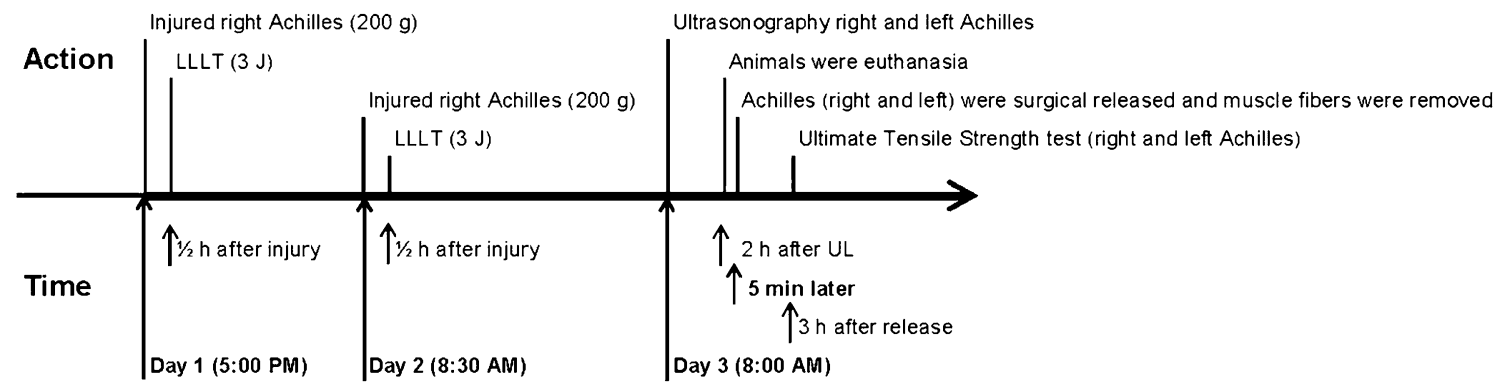

Fig. 2 The experiment time schedule

procedure was used for the left Achilles, and on all animals. This was carried out by J.J.

6. The tendons were subjected to UTS testing $3 \mathrm{~h}$ after release. The proximal end of the Achilles tendon was sprinkled with $250 \mu \mathrm{m}$ alumina powder before it was gripped in a clamp to prevent sliding. A special conically designed grip for the distal end of Achilles tendon was used. In this grip the os calcaneus was used as a plug to obtain the optimal tendon grip [31, 32] (Fig. 4). The maximal load for each tendon at failure was recorded. The procedure was performed by OJ.L. and N.R.G.

\section{Statistical analysis}

Differences between injured right Achilles and healthy left Achilles tendons were analyzed using a paired $t$-test, and differences between groups were analyzed using the $t$-test in SPSS (version 18) from Microsoft.

\section{Results}

The thickness of the injured right and the healthy left Achilles tendons in the longitudinal US images were significantly different $(p<0.05)$ in the active LLLT group (Table 1), but were not significantly different in the placebo LLLT group ( $p=0.35$; Table 1$)$. The mean thickness of the injured right Achilles tendon was $0.93 \pm 0.03 \mathrm{~mm}$ in the active LLLT group and $0.73 \pm 0.07 \mathrm{~mm}$ in the placebo LLLT group, and the mean thickness of the healthy left Achilles tendon (including the peritendon) was $0.69 \pm 0.07 \mathrm{~mm}$ and $0.70 \pm 0.10 \mathrm{~mm}$, respectively.

In the transverse US images the difference between the injured right and the healthy left Achilles tendon was
Fig. 3 Longitudinal US images with tendon thickness measurements. Active LLLT group 2) left and right Achilles tendon (rat 5), $0.70 \mathrm{~mm}$ and $0.93 \mathrm{~mm}$, respectively
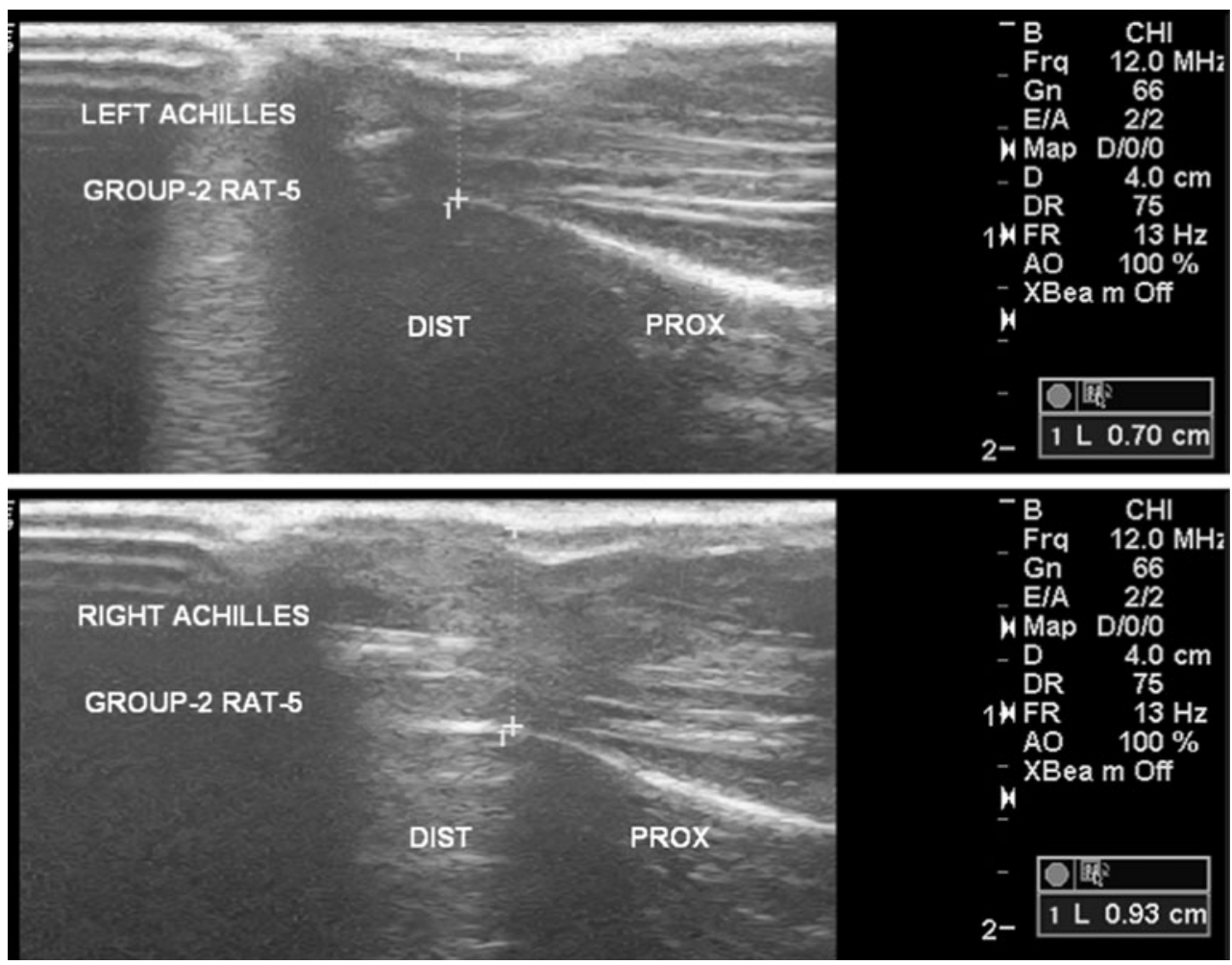


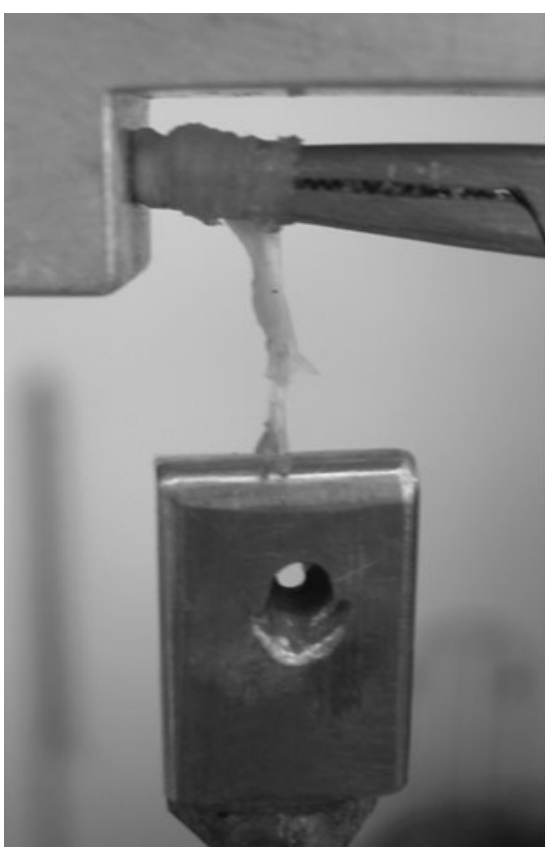

Fig. 4 A rat Achilles tendon at the moment of rupture during UTS testing

significant $(p<0.05)$ in the active LLLT group (Table 1$)$, but was not significant the placebo LLLT group $(p=0.16$; Table 1). The mean transverse thickness of the injured right Achilles tendon was $0.70 \pm 0.10 \mathrm{~mm}$ in the active LLLT group and $0.63 \pm 0.14 \mathrm{~mm}$ in the placebo LLLT group. The mean thickness of the healthy left Achilles tendon in the two groups was $0.51 \pm 0.07 \mathrm{~mm}$ and $0.57 \pm 0.07 \mathrm{~mm}$, respectively.

There were no significant differences in UTS between the injured right and healthy left Achilles tendon in the active LLLT group or in the placebo LLLT group (Table 1). The mean UTS in the injured right Achilles tendon was $51.11 \pm 9.77 \mathrm{~N}$ in the active LLLT group and $57.64 \pm 7.80 \mathrm{~N}$ in the placebo LLLT group. The mean UTS in the healthy left Achilles tendon was $53.94 \pm 9.80 \mathrm{~N}$ in the active LLLT group and $59.66 \pm 11.86 \mathrm{~N}$ in the placebo LLLT group.

\section{Discussion}

Biomechanical test methods are commonly used in the evaluation of surgically induced tendon injuries [31-33]. The UTS values are fairly low during the first 2 weeks after tenotomy and previous studies have avoided UTS testing in models where tendons are not seriously weakened by sharp trauma. Measuring UTS after tendon injury induced by a mini guillotine has to our knowledge not previously been reported in the literature. After a standardized injury in a mini guillotine, rat tendons show histopathological changes [9-11]. However, we found no differences in the biomechanical properties as revealed by UTS between injured and healthy rat Achilles tendons 1-2 days after injury. Similar UTS values have been found in rat Achilles tendons subjected to carrageenan injection [34].

A major technical challenge in UTS testing of healthy rat Achilles tendons is to obtain a reliable, nonsliding grip of the proximal end of the tendon. We have found only two studies investigating UTS of healthy rat Achilles tendons, possibly because grip slippage before the tendon ruptures. In this study we succeeded in developing a grip with a combination of rolling the tendon around conical anchors, and the application of alumina powder to enhance friction. Thus, grip-induced rupture was avoided, and most tendons ruptured a few millimeters from the distal grip with forces up to $75.2 \mathrm{~N}$.

The standard deviation of the UTS of healthy rat Achilles tendons is $\pm 10 \mathrm{~N}$ (present results, and references [14] and [34]) and the difference between healthy and injured tendons is typically $2-3 \mathrm{~N}$. Thus, in future studies with the mini guillotine and UTS, the injury procedure will have to be refined in order to weaken the tendon sufficiently to obtain significant decreases in UTS values after injury.

An irradiation dose of $3 \mathrm{~J}$ is commonly used in clinical practice in human inflammatory conditions and was taken from the dose recommendations of the World Association for Laser Therapy (WALT) [35]. In retrospect, this may

Table 1 Thickness (means \pm SD) of the injured and healthy Achilles tendons and mean differences in thickness as measured by US and UTS ( $n=8$ )

\begin{tabular}{|c|c|c|c|c|c|c|c|}
\hline & \multirow[t]{2}{*}{ Group } & \multirow[t]{2}{*}{ View } & \multicolumn{3}{|c|}{ Tendon thickness (mm) } & \multirow[t]{2}{*}{$95 \% \mathrm{CI}$} & \multirow[t]{2}{*}{$p$ value } \\
\hline & & & Right (injured) & Left (healthy) & Difference (injured-healthy) & & \\
\hline \multirow[t]{4}{*}{ US } & \multirow[t]{2}{*}{ Placebo LLLT } & Longitudinal & $0.73 \pm 0.03$ & $0.70 \pm 0.10$ & $0.03 \pm 0.09$ & -0.04 to 0.11 & 0.35 \\
\hline & & Transverse & $0.63 \pm 0.14$ & $0.57 \pm 0.07$ & $0.07 \pm 0.12$ & -0.03 to 0.17 & 0.16 \\
\hline & \multirow[t]{2}{*}{ Active LLLT } & Longitudinal & $0.93 \pm 0.03$ & $0.69 \pm 0.07$ & $0.24 \pm 0.07$ & 0.18 to 0.30 & $0.00 *$ \\
\hline & & Transverse & $0.70 \pm 0.10$ & $0.51 \pm 0.07$ & $0.19 \pm 0.10$ & 0.10 to 0.27 & $0.00^{*}$ \\
\hline \multirow[t]{2}{*}{ UTS } & Placebo LLLT & & $57.64 \pm 7.80$ & $59.66 \pm 11.86$ & $-2.02 \pm 15.09$ & -14.64 to 10.60 & 0.72 \\
\hline & Active LLLT & & $51.11 \pm 9.77$ & $53.94 \pm 9.80$ & $-2.83 \pm 10.76$ & -11.82 to 6.16 & 0.48 \\
\hline
\end{tabular}

$* p \leq 0.05$. 
have been too high for rat Achilles tendon pathology. Optimal irradiation doses from 904-nm lasers in rat muscles seem to be closer to $1 \mathrm{~J}$. In a new study with LLLT, doses of $0.1,0.3,1.0$ and $3.0 \mathrm{~J}$ were used to prevent skeletal muscle fatigue and possible muscle damage. All irradiated groups except the group irradiated at a dose of $3.0 \mathrm{~J}$ had significantly lower post-exercise creatine kinase activity than the control group immediately after the contraction tests [36]. If these doses translate to rat Achilles tendons, it could explain the nonsignificant differences, but not the increased edema observed in the active LLLT group.

In the current study there was an interval of $15 \mathrm{~h}$ between the two LLLT irradiations. There are very few studies in which there was an interval of less than $24 \mathrm{~h}$ between irradiations. Thus, we cannot rule out the possibility that an interval of $15 \mathrm{~h}$ was too short and resulted in negative effects of LLLT. This is clearly an area where more research is needed. A more likely explanation for the increased edema in the active LLLT group could be an indirect consequence of symptomatic pain reduction from LLLT leading to increased activity causing more edema $[37,38]$. Reduced pain sensation from the injured tissue could promote physical activity, and this may result in a temporary increase in edema at the site of injury during the $23 \mathrm{~h}$ between the LLLT irradiation session and the US examination [39].

The timing of LLLT irradiation in the acute phase of inflammation is seldom discussed in the literature, but it can be crucial for achieving positive effects. In some animal studies, LLLT treatment has been found to reduce edema, and is typically been measured 4 hours after injury [40-42]. Thus, we did not expect to find an increase in edema after a single LLLT treatment $30 \mathrm{~min}$ after injury. We speculate that the unexpected differences between the results may be explained by differences in study design. Scrutiny of the design of other similar LLLT studies showed that LLLT has mainly been administered later than 30 min after injury [42] and/or that the treatment procedure included more than a single LLLT session [2, 3, 9, 21, 40, 41].

It is known that LLLT energy acts on biological processes [43]. We therefore considered the cascade of responses in the acute phase of inflammation, and in particular which processes are dominant in the first half hour. The immediate response in the innate immunity after an injury is activation of signal transduction mechanisms. Immediate genes activated within the first half hour of inflammation are mainly transcription factors [44, 45]. Among these expressed cytokine gene is mitogen-activated protein kinase (MAPK) [46]. Three well-characterized subfamilies of MAPK are stress-activated protein kinases/ c-Jun N-terminal kinase (JNK), p38 mitogen-activated protein kinase (p38) and extracellular regulated protein kinases (ERK) [44, 47, 48]. Peak times for kinases have been established for JNK, p38 and ERK in tendon cells, smooth muscle cells, endothelial cells and cardiac fibroblasts. JNK, p38 and ERK increase rapidly, and they reach a maximum within 10 to $30 \mathrm{~min}$ [49-52]. The impact of JNK, p38 and ERK on edema has been investigated in rodent paw models and brain injury models using inhibitors for JNK, p38 and ERK, respectively. Tested selectively, all these inhibitors reduce the development of edema, and consequently JNK, p38 and ERK may increase edema development [53-56].

The effect from LLLT (632.8 nm, $4.5 \mathrm{~mW})$ on JNK, p38 and ERK has been investigated in skeletal muscle cells. LLLT does not increase JNK and p38 activation or protein expression, but LLLT induces protein translation through ERK pathways $[57,58]$. Perhaps the unexpected increase in edema development in the LLLT group in our study can be explained through a stimulation of the ERK pathway. But this is speculative as we did not measure any of the outcomes needed to confirm or refute this theory.

We also explored studies with LLLT irradiation within the first half hour after injury (injection or surgery) with regard to edema development. In a previous study by members of our research group [40], different timing protocols for LLLT $(650 \mathrm{~nm})$ were used. Carrageenan was injected into rat paws and edema was measured 1 to $4 \mathrm{~h}$ later. The main conclusion was that LLLT has an antiinflammatory effect in most cases, but one group treated with LLLT had developed increased edema $10 \mathrm{~min}$ after injection compared to controls.

Some clinical studies in dentistry have evaluated the effect of LLLT on edema development immediately after surgery [59-64]. The timing of LLLT administration was not explicitly reported, but in two studies report the duration of surgery was $19 \min [63,64]$. In one study, LLLT given immediately after surgery was found to have increased edema at 3 days, but not at 7 days [62]. Two studies with adequate doses found reduced edema [63, 64]. In three studies LLLT doses did not meet the WALT dose recommendations for LLLT. One study used a scanning mode for application of the laser beam [61], and the other two used doses that were too low $(<1 \mathrm{~J})[59,60]$.

Even though the results regarding edema development in studies in which LLLT was used within the first half hour after injury are arbitrary, it is not unlikely that LLLT irradiation within the first half hour after an injury will temporarily increase edema. This finding has important clinical implications, as it has been an open question as to when is the earliest time-point for effective LLLT administration. Interestingly, in some studies LLLT has been administered before muscle damage or the onset of inflammatory process with good results on other outcome measures $[36,65]$. This indicates that the negative effect on edema development is restricted to inflamed tissue and the first half hour after the onset of inflammation. 
Our decision to use the mini guillotine model was an attempt to mimic a tendon disorder with inflammatory components. Signs of inflammation are present in acute and mild tendinopathies $[66,67]$. In previous studies using the mini guillotine injury method in rodents, the injured tendons have shown inflammatory reactions [9-11]. The significant increase in thickness of the injured tendons supports the suitability of the mini guillotine model for causing Achilles tendinopathy in the rat. The mini guillotine model has the advantage of being easier to use than overuse models such as the treadmill running model of Soslowsky et al. [68]. None of these models involves penetration of the skin and therefore they avoid the risk of infection during the injury procedure. The surgical procedure of tenotomy does introduce a risk for infection, and it may also be questioned as to how relevant this model for investigation of tendinopathies.

The use of animal models in research on human tendinopathies has its limitations. There are obvious anatomical differences between bipeds and quadrupeds. This affects the validity of using animal models to study tendinopathies, and limits extrapolation of the findings in animal studies to human tendinopathies. Whether effective laser parameters in small rodent models can be extrapolated to humans remains uncertain and additional clinical studies in humans to verify or repute the findings are called for.

\section{Conclusion}

Laser irradiation at $0.158 \mathrm{~W} / \mathrm{cm}^{2}$ for $50 \mathrm{~s}(3 \mathrm{~J})$ administered within the first half hour after two blunt trauma injuries $15 \mathrm{~h}$ apart appeared to increase edema in the rat Achilles tendon measured at $23 \mathrm{~h}$ after LLLT.

The UTS of the rat Achilles tendon was not decreased significantly after two blunt traumas inflicted by a mini guillotine. This experimental model appears useful for investigating the optimal timing and effect of therapies in acute tendon injuries. In this model, edema can be reliably measured by US, and tendon UTS can be reliably tested in both healthy and weakened rat Achilles tendons. There is a need to further refine the experimental procedure to achieve a weakening of the rat Achilles tendon. Further studies with this model should include variations in the intervals between traumas, the timing of treatment, the number of LLLT sessions and the power densities.

Open Access This article is distributed under the terms of the Creative Commons Attribution Noncommercial License which permits any noncommercial use, distribution, and reproduction in any medium, provided the original author(s) and source are credited.

\section{References}

1. Reddy GK, Stehno-Bittel L, Enwemeka CS (1998) Laser photostimulation of collagen production in healing rabbit Achilles tendons. Lasers Surg Med 22(5):281-287

2. Carrinho PM, Renno AC, Koeke P, et al (2006) Comparative study using $685-\mathrm{nm}$ and $830-\mathrm{nm}$ lasers in the tissue repair of tenotomized tendons in the mouse. Photomed Laser Surg 24 (6):754-758

3. Arruda E, Rodrigues N, Taciro C, Parizotto N (2007) Influences of different low level laser therapy wavelengths in rat tendon regeneration after tenotomy. Rev Bras Fisioter 11 (4):247-252

4. Elwakil TF (2007) An in-vivo experimental evaluation of $\mathrm{He}-\mathrm{Ne}$ laser photostimulation in healing Achilles tendons. Lasers Med Sci 22(1):53-59.

5. Ng GY, Fung DT (2008) The combined treatment effects of therapeutic laser and exercise on tendon repair. Photomed Laser Surg 26(2):137-141

6. Chan HK, Fung DT, Ng GY (2007) Effects of low-voltage microamperage stimulation on tendon healing in rats. J Orthop Sports Phys Ther 37(7):399-403

7. Yeung CK, Guo X, Ng YF (2006) Pulsed ultrasound treatment accelerates the repair of Achilles tendon rupture in rats. J Orthop Res 24(2):193-201

8. See EK, Ng GY, Ng CO, Fung DT (2004) Running exercises improve the strength of a partially ruptured Achilles tendon. Br J Sports Med 38(5):597-600

9. Salate AC, Barbosa G, Gaspar P, et al (2005) Effect of In-Ga-Al-P diode laser irradiation on angiogenesis in partial ruptures of Achilles tendon in rats. Photomed Laser Surg 23(5):470-475

10. Fillipin LI, Mauriz JL, Vedovelli K, et al (2005) Low-level laser therapy (LLLT) prevents oxidative stress and reduces fibrosis in rat traumatized Achilles tendon. Lasers Surg Med 37 (4):293-300

11. Oliveira FS, Pinfildi CE, Parizoto NA, et al (2009) Effect of low level laser therapy $(830 \mathrm{~nm})$ with different therapy regimes on the process of tissue repair in partial lesion calcaneus tendon. Lasers Surg Med 41(4):271-276

12. Nordin M, Frankel VH (2001) Basic biomechanics of the musculoskeletal system, 3rd edn. Lippincott Williams \& Wilkins, Baltimore

13. Kilkelly FX, Choma TJ, Popovic N, et al (1996) Tendon repair by laser welding: a histologic and biomechanical comparison and suture repair with $\mathrm{CO} 2$ and argon lasers. Lasers Surg Med 19:487-491

14. Wieloch P, Buchmann G, Roth W, Rickert M (2004) A cryo-jaw designed for in vitro tensile testing of the healing Achilles tendons in rats. J Biomech 37(11):1719-1722

15. Karu T (1999) Primary and secondary mechanisms of action of visible to near-IR radiation on cells. J Photochem Photobiol B 49 (1):1-17

16. Karu TI (2008) Mitochondrial signaling in mammalian cells activated by red and near-IR radiation. Photochem Photobiol 84 (5):1091-1099

17. Karu TI, Pyatibrat LV, Kolyakov SF, Afanasyeva NI (2008) Absorption measurements of cell monolayers relevant to mechanisms of laser phototherapy: reduction or oxidation of cytochrome c oxidase under laser radiation at $632.8 \mathrm{~nm}$. Photomed Laser Surg 26(6):593-599

18. Gao X, Xing D (2009) Molecular mechanisms of cell proliferation induced by low power laser irradiation. J Biomed Sci 16:4

19. Moriyama Y, Nguyen J, Akens M, Moriyama EH, Lilge L (2009) In vivo effects of low level laser therapy on inducible nitric oxide synthase. Lasers Surg Med 41(3):227-231 
20. Aimbire F, Albertini R, Pacheco MT, et al (2006) Low-level laser therapy induces dose-dependent reduction of TNFalpha levels in acute inflammation. Photomed Laser Surg 24(1):3337

21. Correa F, Lopes Martins RA, Correa JC, et al (2007) Low-level laser therapy $(\mathrm{GaAs}$ lambda $=904 \mathrm{~nm})$ reduces inflammatory cell migration in mice with lipopolysaccharide-induced peritonitis. Photomed Laser Surg 25(4):245-249

22. Silverstein BA, Viikari-Juntura E, Fan ZJ, et al (2006) Natural course of nontraumatic rotator cuff tendinitis and shoulder symptoms in a working population. Scand J Work Environ Health 32(2):99-108

23. Lian OB, Engebretsen L, Bahr R (2005) Prevalence of jumper's knee among elite athletes from different sports: a cross-sectional study. Am J Sports Med 33(4):561-567

24. Darre EM, Klokker M, Lund P, et al (1994) Laser therapy of Achilles tendinitis. Ugeskr Laeger 156(45):6680-6683

25. Murrell GA, Walton JR (2001) Diagnosis of rotator cuff tears. Lancet 357(9258):769-770

26. Warden SJ (2007) Animal models for the study of tendinopathy. Br J Sports Med 41(4):232-240

27. Soslowsky LJ, Thomopoulos S, Tun S, et al (2000) Neer Award 1999. Overuse activity injures the supraspinatus tendon in an animal model: a histologic and biomechanical study. J Shoulder Elbow Surg 9(2):79-84

28. Jacobson JA (2009) Musculoskeletal ultrasound: focused impact on MRI. AJR Am J Roentgenol 193(3):619-627

29. Warden SJ, Kiss ZS, Malara FA, et al (2007) Comparative accuracy of magnetic resonance imaging and ultrasonography in confirming clinically diagnosed patellar tendinopathy. Am J Sports Med 35(3):427-436

30. Campbell RS, Grainger AJ (2001) Current concepts in imaging of tendinopathy. Clin Radiol 56(4):253-267

31. Dimmen S, Engebretsen L, Nordsletten L, Madsen JE (2009) Negative effects of parecoxib and indomethacin on tendon healing: an experimental study in rats. Knee Surg Sports Traumatol Arthrosc 17(7):835-839

32. Forslund C, Bylander B, Aspenberg P (2003) Indomethacin and celecoxib improve tendon healing in rats. Acta Orthop Scand 74 (4):465-469

33. Forslund C, Aspenberg P (2001) Tendon healing stimulated by injected CDMP-2. Med Sci Sports Exerc 33(5):685-687

34. Marsolais D, Duchesne E, Cote CH, Frenette J (2007) Inflammatory cells do not decrease the ultimate tensile strength of intact tendons in vivo and in vitro: protective role of mechanical loading. J Appl Physiol 102(1):11-17

35. World Association for Laser Therapy (2010) Dosage recommendations. Recommended treatment doses for low level laser therapy. http://www.walt.nu/dosage-recommendations.html. Accessed 27 Apr 2011

36. Leal Junior EC, Lopes-Martins RA, de Almeida P, et al (2010) Effect of low-level laser therapy (GaAs $904 \mathrm{~nm}$ ) in skeletal muscle fatigue and biochemical markers of muscle damage in rats. Eur J Appl Physiol 108(6):1083-1088

37. Bjordal JM, Couppe C, Chow RT, Tuner J, Ljunggren EA (2003) A systematic review of low level laser therapy with locationspecific doses for pain from chronic joint disorders. Aust J Physiother 49(2): 107-116

38. Bjordal JM, Lopes-Martins RA, Joensen J, et al (2008) A systematic review with procedural assessments and metaanalysis of low level laser therapy in lateral elbow tendinopathy (tennis elbow). BMC Musculoskelet Disord 9:75

39. Slatyer MA, Hensley MJ, Lopert R (1997) A randomized controlled trial of piroxicam in the management of acute ankle sprain in Australian Regular Army recruits. The Kapooka Ankle Sprain Study. Am J Sports Med 25(4):544-553
40. Albertini R, Aimbire FS, Correa FI, et al (2004) Effects of different protocol doses of low power gallium-aluminum-arsenate (Ga-Al-As) laser radiation $(650 \mathrm{~nm})$ on carrageenan induced rat paw oedema. J Photochem Photobiol B 74(2-3):101-107

41. Barbosa AM, Villaverde AB, Guimarães-Souza L, et al (2008) Effect of low-level laser therapy in the inflammatory response induced by Bothrops jararacussu snake venom. Toxicon 51 (7):1236-1244

42. Bortone F, Santos HA, Albertini R, et al (2008) Low level laser therapy modulates kinin receptors mRNA expression in the subplantar muscle of rat paw subjected to carrageenan-induced inflammation. Int Immunopharmacol 8(2):206-210

43. Karu T (2007) Ten lectures on basic science of laser phototherapy. Prima Books, Grängesberg, Sweden

44. Kindt TJ, Goldsby RA, Osborne BA (2007) Kuby immunology, 6th edn. Freeman, New York

45. Koj A (1996) Initiation of acute phase response and synthesis of cytokines. Biochim Biophys Acta 1317(2):84-94

46. Pearson G, Robinson F, Beers Gibson T, et al (2001) Mitogenactivated protein (MAP) kinase pathways: regulation and physiological functions. Endocr Rev 22(2):153-183

47. Zarubin T, Han J (2005) Activation and signaling of the p38 MAP kinase pathway. Cell Res 15(1):11-18

48. Robinson MJ, Cobb MH (1997) Mitogen-activated protein kinase pathways. Curr Opin Cell Biol 9(2):180-186

49. MacKenna DA, Dolfi F, Vuori K, Ruoslahti E (1998) Extracellular signal-regulated kinase and c-Jun NH2-terminal kinase activation by mechanical stretch is integrin-dependent and matrix-specific in rat cardiac fibroblasts. J Clin Invest 101(2):301-310

50. Arnoczky SP, Tian T, Lavagnino M, et al (2002) Activation of stress-activated protein kinases (SAPK) in tendon cells following cyclic strain: the effects of strain frequency, strain magnitude, and cytosolic calcium. J Orthop Res 20(5):947-952

51. Kyaw M, Yoshizumi M, Tsuchiya K, Kirima K, Tamaki T (2001) Antioxidants inhibit JNK and p38 MAPK activation but not ERK $1 / 2$ activation by angiotensin II in rat aortic smooth muscle cells. Hypertens Res 24(3):251-261

52. Werle M, Schmal U, Hanna K, Kreuzer J (2002) MCP-1 induces activation of MAP-kinases ERK, JNK and p38 MAPK in human endothelial cells. Cardiovasc Res 56(2):284-292

53. Claudino RF, Kassuya CA, Ferreira J, Calixto JB (2006) Pharmacological and molecular characterization of the mechanisms involved in prostaglandin E2-induced mouse paw edema. $\mathrm{J}$ Pharmacol Exp Ther 318(2):611-618

54. Yatsushige H, Ostrowski RP, Tsubokawa T, Colohan A, Zhang JH (2007) Role of c-Jun N-terminal kinase in early brain injury after subarachnoid hemorrhage. J Neurosci Res 85(7):1436-1448

55. Chopra P, Kulkarni O, Gupta S, et al (2010) Pharmacological profile of AW-814141, a novel, potent, selective and orally active inhibitor of p38 MAP kinase. Int Immunopharmacol 10(4):467473

56. Mori T, Wang X, Aoki T, Lo EH (2002) Downregulation of matrix metalloproteinase-9 and attenuation of edema via inhibition of ERK mitogen activated protein kinase in traumatic brain injury. J Neurotrauma 19(11):1411-1419

57. Shefer G, Oron U, Irintchev A, Wernig A, Halevy O (2001) Skeletal muscle cell activation by low-energy laser irradiation: a role for the MAPK/ERK pathway. J Cell Physiol 187(1):73-80

58. Shefer G, Partridge TA, Heslop L, et al (2002) Low-energy laser irradiation promotes the survival and cell cycle entry of skeletal muscle satellite cells. J Cell Sci 115(Pt 7):1461-1469

59. Taube S, Piironen J, Ylipaavalniemi P (1990) Helium-neon laser therapy in the prevention of postoperative swelling and pain after wisdom tooth extraction. Proc Finn Dent Soc 86(1):23-27

60. Carrillo JS, Calatayud J, Manso FJ, et al (1990) A randomized double-blind clinical trial on the effectiveness of helium-neon 
laser in the prevention of pain, swelling and trismus after removal of impacted third molars. Int Dent J 40:31-36

61. Fernando S, Hill CM, Walker R (1993) A randomised double blind comparative study of low level laser therapy following surgical extraction of lower third molar teeth. Br J Oral Maxillofac Surg 31(3): 170-172

62. Roynesdal AK, Bjornland T, Barkvoll P, Haanaes HR (1993) The effect of soft-laser application on postoperative pain and swelling. A double-blind, crossover study. Int J Oral Maxillofac Surg 22 (4):242-245

63. Markovic A, Todorovic L (2007) Effectiveness of dexamethasone and low-power laser in minimizing oedema after third molar surgery: a clinical trial. Int J Oral Maxillofac Surg 36(3):226-229

64. Aras MH, Gungormus M (2010) Placebo-controlled randomized clinical trial of the effect two different low-level laser therapies (LLLT) - intraoral and extraoral - on trismus and facial swelling following surgical extraction of the lower third molar. Lasers Med Sci 25(5):641-645

65. Lopes-Martins RA, Marcos RL, Leonardo PS, et al (2006) Effect of low-level laser (Ga-Al-As $655 \mathrm{~nm}$ ) on skeletal muscle fatigue induced by electrical stimulation in rats. J Appl Physiol 101 (1):283-288

66. Torp-Pedersen TE, Torp-Pedersen ST, Qvistgaard E, Bliddal H (2008) Effect of glucocorticosteroid injections in tennis elbow verified on colour Doppler ultrasonography: evidence of inflammation. Br J Sports Med 42(12):978-982

67. Millar NL, Hueber AJ, Reilly JH, et al (2010) Inflammation is present in early human tendinopathy. Am J Sports Med 38 (10):2085-2091

68. Soslowsky LJ, Carpenter JE, DeBano CM, Banerji I, Moalli MR (1996) Development and use of an animal model for investigations on rotator cuff disease. J Shoulder Elbow Surg 5(5):383-392 